\title{
Impairment of Cardiac Function and Energetics in Experimental Renal Failure
}

A. E. G. Raine, A.-M. L. Seymour, * A. F. C. Roberts, G. K. Radda, * and J. G. G. Ledingham

Nuffield Department of Clinical Medicine, John Radcliffe Hospital, *Department of Biochemistry, South Parks Road, Oxford OX3 9DU, England

\begin{abstract}
Cardiac function and energetics in experimental renal failure in the rat ( $5 / 6$ nephrectomy) have been investigated by means of an isolated perfused working heart preparation and an isometric Langendorff preparation using ${ }^{31} \mathrm{P}$ nuclear magnetic resonance $\left({ }^{31} \mathrm{P}\right.$ NMR $) .4$ wk after nephrectomy cardiac output of isolated hearts perfused with Krebs-Henseleit buffer was significantly lower $(P<0.0001)$ at all levels of preload and afterload in the renal failure groups than in the pair-fed sham operated control group. In control hearts, cardiac output increased with increases in perfusate calcium from 0.73 to $5.61 \mathrm{mmol} /$ liter whereas uremic hearts failed in high calcium perfusate.

Collection of ${ }^{31} \mathrm{P}$ NMR spectra from hearts of renal failure and control animals during $\mathbf{3 0}$ min normoxic Langendorff perfusion showed that basal phosphocreatine was reduced by $32 \%$ to $4.7 \mu \mathrm{mol} / \mathrm{g}$ wet wt $(P<0.01)$ and the phosphocreatine to ATP ratio was reduced by $32 \%(P<0.01)$ in uremic hearts. During low flow ischemia, there was a substantial decrease in phosphocreatine in the uremic hearts and an accompanying marked increase in release of inosine into the coronary effluent (14.9 vs 6.1 $\mu \mathrm{M}, P<0.01$ ).

We conclude that cardiac function is impaired in experimental renal failure, in association with abnormal cardiac energetics and increased susceptibility to ischemic damage. Disordered myocardial calcium utilization may contribute to these derangements. (J. Clin. Invest. 1993. 92:2934-2940.) Key words: uremia $\bullet$ heart failure $\cdot$ calcium ${ }^{31} \mathrm{P}$ nuclear magnetic resonance $\bullet$ myocardial ischemia
\end{abstract}

\section{Introduction}

More than half of all deaths in end-stage renal failure are from cardiovascular events. Of these, death from cardiac causes is especially common, accounting for $\sim 40 \%$ of all deaths in patients maintained on hemodialysis (1). Many factors have been proposed to contribute to the cardiac complications of chronic renal failure, including hypertension, fluid overload, pericardial disease, anemia, and coronary atherosclerosis (2). Previous experimental studies have also suggested that metabolic abnormalities characteristic of uremia, such as elevated blood urea (3) and secondary hyperparathyroidism (4), might

Address correspondence to Prof. A. E. G. Raine, Department of Nephrology, St. Bartholomew's Hospital, West Smithfield, London EC1A 7BE, England. 1993.

Received for publication 2 July 1992 and in revised form 8 June

J. Clin. Invest.

(C) The American Society for Clinical Investigation, Inc.

$0021-9738 / 93 / 12 / 2934 / 07 \$ 2.00$

Volume 92, December 1993, 2934-2940 adversely affect cardiac function. Furthermore, in dialysis patients, Rostand and colleagues observed that the prevalence of symptomatic ischemic heart disease greatly exceeded the presence of significant coronary artery narrowing (5), raising the possibility that myocardial metabolism and oxygen demand may be altered in chronic renal failure.

The hypothesis the present study aimed to investigate was that in chronic renal failure, cardiac energetics may be abnormal, resulting in impaired cardiac performance and increased susceptibility to ischemia. Previous studies of cardiac function in vivo have given conflicting results. Acute uremia of 24-48 h duration led to increased myocardial contractility in rats (6, 7 ), and dogs (8), whereas myocardial function was unchanged from controls after $7 \mathrm{~d}$ of uremia in both species $(9,10)$. As interpretation of studies performed in vivo may be complicated by reflex neural and hormonal effects, in the present study, cardiac function, energetics, and susceptibility to ischemia have been investigated in experimental chronic uremia in vitro, by means of an isolated working heart preparation and ${ }^{31} \mathrm{P}$ nuclear magnetic resonance $\left({ }^{31} \mathrm{P} \mathrm{NMR}\right){ }^{1}$ of hearts perfused by a modified Langendorff technique.

\section{Methods}

\section{Experimental model}

Male Wistar rats weighing 200-240 g were used. Renal impairment was produced by subtotal nephrectomy (11). Rats were anesthetized with 1 $\mathrm{ml} / 100 \mathrm{~g} 5 \%$ chloral in $0.9 \% \mathrm{NaCl}$, a midline incision was made, the left kidneys were isolated and approximately two thirds (500-600 mg tissue) of the renal parenchyma cut away. Sham-operated control rats were anesthetized, and the left kidneys were decapsulated. $7 \mathrm{~d}$ later, the rats were again anesthetized with $5 \%$ chloral and the right kidney was removed through a flank incision, with preservation of the adrenal gland. Sham-operated controls were anesthetized, and the right kidneys were exposed, and perinephric fat removed from the otherwise intact kidney.

$1 \mathrm{~d}$ after completion of surgery, all animals were housed in individual cages, and were pair fed. Daily food intake of uremic rats was measured and the same quantity of food was given to the allocated paired sham operated control the following day. The diet contained $16.7 \%$ protein and $0.21 \%$ sodium (Beekay Feeds, Hull, England). Animals had free access to tap water and were weighed daily. For measurement of systolic blood pressure without anesthesia, rats were acclimatised to restraining cages for $2 \mathrm{~d}$, and the pressure was recorded using a tail cuff and sphygmomanometer (Narco Bio-Systems, Inc., Houston, TX) on the 3rd d, $21 \mathrm{~d}$ after surgery. Four to five measurements of systolic blood pressure were made over a 60 -min period, and their mean was calculated. Hematocrit and plasma urea, creatinine, and electrolytes were measured on the 7th, 14th and 28th $\mathrm{d}$ after operation by taking a $1-\mathrm{ml}$ sample from the tail artery under ether anesthesia. Hematocrit was measured by microcentrifugation, and sodium, potas-

1. Abbreviations used in this paper: MANOVA, multiple analysis of variance; ${ }^{31} \mathrm{P} \mathrm{NMR},{ }^{31} \mathrm{P}$ nuclear magnetic resonance. 
sium, urea, and creatinine were measured by automated analyzer. Plasma ionized calcium was measured by Nova 2 analyzer. (V. A. Howe and Co., Banbury, United Kingdom)

\section{Isolated perfused working heart}

$28 \mathrm{~d}$ after right nephrectomy, rats were anesthetised intraperitoneally with pentobarbital $100 \mathrm{mg} / \mathrm{kg}, 100 \mathrm{U}$ heparin was given intravenously, the hearts were removed and immediately placed in ice-cold saline. The aorta was cannulated and perfused with oxygenated Krebs Henseleit bicarbonate saline solution containing $2.5 \mathrm{mM} \mathrm{Ca}^{2+}$ and $10 \mathrm{mM}$ glucose substrate as previously described $(12,13)$. Hearts were kept at constant temperature $\left(37^{\circ} \mathrm{C}\right)$ via a water-jacketed perfusion chamber throughout the experiments.

Perfusion protocol. Single-pass perfusion was begun through the aortic cannula at a hydrostatic pressure of $80 \mathrm{~cm} \mathrm{H}_{2} \mathrm{O}$, and continued for 3-4 min, to wash all blood from the coronary circulation. During this time, the left atrium was cannulated. Recirculating perfusion via the left atrium was then commenced, and left atrial reservoir filling pressure (preload) and aortic pressure head (afterload) were independently varied to enable determination of left ventricular function curves (13). Left atrial filling pressure was initially held constant at $17.5 \mathrm{~cm} \mathrm{H} \mathrm{H}_{2} \mathrm{O}$, and aortic overflow height (aortic pressure) was set successively at 5 -min intervals at $70,100,130$, and $160 \mathrm{~cm} \mathrm{H}_{2} \mathrm{O}$ to document the relationship between afterload and cardiac output. Aortic pressure was then held constant at $100 \mathrm{~cm} \mathrm{H}_{2} \mathrm{O}$ and left atrial filling pressure set at 7.5, 12.5, 17.5, and finally $22.5 \mathrm{~cm} \mathrm{H}_{2} \mathrm{O}$ to determine the preload cardiac output relationship (Starling curve). At each pressure setting, cardiac output and coronary flow were measured by timed collection of perfusate as previously described (12). Heart rate and aortic pressure were recorded continuously through a side arm in the aortic cannula, using a fluid-filled system with a transducer (PDCR75; Druck Ltd., Groby, Leicester, United Kingdom ) attached to a recorder and 4820 preamplifier (MX216 and 4820, respectively; Lectromed Ltd., Letchworth, Herts, United Kingdom ).

After determination of function curves, the perfusate calcium concentration was reduced to $0.7 \mathrm{mM}$, cardiac output and heart rate were measured, and then at 5-min intervals, the perfusate calcium concentration was increased to $1.5,2.9$, and $5.6 \mathrm{mM}$, with repeated measurements of cardiac function. At the end of the protocol, hearts were blotted and dried in a tissue oven at $70^{\circ} \mathrm{C}$ until constant weight was achieved, to determine dry weight.

\section{Acute effects of urea and creatinine on cardiac function}

Hearts from control male Wistar rats weighing 320-340 g were perfused as described above, with a left atrial pressure of $17.5 \mathrm{~cm} \mathrm{H}_{2} \mathrm{O}$ and aortic pressure of $100 \mathrm{~cm} \mathrm{H}_{2} \mathrm{O}$. After $20 \mathrm{~min}$ of control observations, urea $(n=6)$ or creatinine $(n=6)$ was added to the perfusion reservoir at 10 -min intervals to achieve final concentrations of 75 and 150 $\mathrm{mmol} /$ liter (urea) and 1,000 and $2,000 \mu \mathrm{mol} /$ liter (creatinine). Cardiac output, coronary flow, and heart rate were recorded at 2-min intervals.

\section{${ }^{31} P$ NMR studies}

Seven male Wistar rats $(180-200 \mathrm{~g})$ were made uremic by subtotal nephrectomy, as described above, with sham-operated pair-fed animals as controls. One control animal was lost during the experimental protocol. After $21 \mathrm{~d}$, animals were anesthetized with diethyl ether and injected intravenously with heparin $(1,000 \mathrm{U} / \mathrm{ml}),-1.0 \mathrm{ml} / \mathrm{kg}$ body wt via the femoral vein. Hearts were then rapidly excised and placed in ice-cold phosphate-free Krebs-Henseleit bicarbonate buffer. The perfusion medium consisted of $118.5 \mathrm{mM} \mathrm{NaCl}, 25 \mathrm{mM} \mathrm{NaHCO}_{3}, 6.0 \mathrm{mM}$ $\mathrm{KCl}, 1.25 \mathrm{mM} \mathrm{CaCl}_{2}$, and $1.25 \mathrm{mM} \mathrm{MgSO}_{4}$ with $11.0 \mathrm{mM}$ glucose as substrate. Hearts were suspended on a glass cannula via the aorta and perfused in Langendorff isometric mode at $70 \mathrm{~cm} \mathrm{H}_{2} \mathrm{O}$ pressure compatible with the ${ }^{31} \mathrm{P}-\mathrm{NMR}$ technique as described previously $(14,15)$. The apex of the heart was attached to a semiconductor strain gauge (Kulite Sensors Ltd., Basingstoke, Hants, United Kingdom), and cardiac function was monitored continuously by measurement of devel- oped tension via the strain gauge. Initially, the tension was set at 10-15 g. The bundle of His was severed and hearts were paced at $300 \mathrm{bpm}$ using platinum electrodes, one located in the aortic cannula and the other delicately inserted into the ventricle. Coronary flow was measured by the timed collection of perfusate.

Concentrations of phosphocreatine, ATP, and inorganic phosphate were determined by ${ }^{31} \mathrm{P}-\mathrm{NMR}$. Spectra were collected at a ${ }^{31} \mathrm{P}$ frequency of $73.836 \mathrm{MHz}$ using a 4.2-T superconducting magnet with an 8-cm bore and spectrometer (Biospec; Bruker Ltd., Coventry, United Kingdom). The probe consisted of a vertically mounted Helmholtz coil ( $2.8 \mathrm{~cm}$ in diameter) tuned to the phosphorus frequency. During a 20-min equilibration period, the magnetic field homogeneity was optimized by shimming on the proton signal of the heart and the surrounding water contained within the sensitive volume of the NMR probe. Quantitative data were obtained from a fully relaxed spectrum accumulated using a $90^{\circ}$ pulse and 7-s interpulse delay. Concentrations were measured by integrating the areas under the resonance peaks of interest and comparing them with that of a standard (methylene diphosphonate) of known concentration contained in a capillary within the radiofrequency coil. Where appropriate peak areas were corrected for partial saturation effects using correction factors determined from spectra acquired using a 7-s delay and a 15-s delay. Intracellular $\mathrm{pH}$ was determined from the chemical shift of the inorganic phosphate resonance peak relative to that of phosphocreatine (16). Subsequently, spectra were collected in 5-min time blocks using a $70^{\circ}$ pulse and 1-s interpulse delay. After a further 20-min of normoxic perfusion, low flow ischemia was produced in four pairs of animals by lowering the perfusion pressure to $15-20 \mathrm{~cm} \mathrm{H}_{2} \mathrm{O}$, to reduce the coronary flow to 1.0 $\mathrm{ml} / \mathrm{min}$ for $30 \mathrm{~min}$. Hearts were then reperfused at a pressure of $70 \mathrm{~cm}$ $\mathrm{H}_{2} \mathrm{O}$ for an additional $20 \mathrm{~min}$. Spectra were acquired throughout this period in 5-min time blocks. Percentage changes in phosphocreatine and ATP were determined throughout the period of low flow ischemia and reperfusion by comparing peak heights with control spectra collected during normoxia (taken as $100 \%$ ). $100 \%$ was considered equivalent to the metabolite concentrations measured using the $90^{\circ}$ pulse and 7-s delay. Coronary flow was monitored at the midpoint of each spectrum. At the same time, a sample of coronary effluent was collected via the sampling line for analysis of inosine release, as a marker of ischemic injury (17). These samples were analyzed using the HPLC method of Harmsen et al. (18).

At the end of the experimental protocol, hearts were freeze clamped, weighed, extracted with $8 \%$ perchloric acid, neutralized, and analyzed for total creatine (creatine plus phosphocreatine) using an HPLC ion exchange method (19).

Free cytosolic ADP was calculated from the creatine kinase equilibrium reaction $\left(K_{\mathrm{eq}}=1.7 \times 10^{9} \mathrm{M}^{-1}\right.$, assuming a free $\mathrm{Mg}^{2+}$ concentration of $1 \mathrm{mM})(20)$,

$$
\text { where } \quad K_{\mathrm{eq}}=\frac{[A T P][C r]}{[P C r]\left[H^{+}\right][A D P]}
$$

\section{Statistics}

Results are expressed as mean \pm SEM. Statistical comparison between uremic and paired control hearts was by means of multiple analysis of variance (MANOVA), using the Stats graphics version 4.0 statistical program, followed by Student's $t$ test for unpaired samples for comparison of individual data points. Comparisons for ${ }^{31} \mathrm{P}$ NMR studies were performed by an unpaired Student's $t$ test.

\section{Results}

Renal failure model. Table I shows the average food intake, final heart and body weight, systolic blood pressure, hematocrit, and plasma biochemistry in the renal failure and control animals after $28 \mathrm{~d}$. Despite pair feeding, uremic animals weighed less than controls $(P<0.05)$. Both the heart dry weight and the heart weight/body weight ratios were increased 
Table I. Characteristics of Uremic and Pair-fed Control Animals

\begin{tabular}{lccc}
\hline & $\begin{array}{c}\text { Uremic } \\
(n=8)\end{array}$ & $\begin{array}{c}\text { Control } \\
(n=8)\end{array}$ & $P$ \\
\hline Average food intake (g/day) & $15.9 \pm 1.3$ & $16.6 \pm 1.4$ & $\mathrm{NS}$ \\
Final body weight $(\mathrm{g})$ & $222 \pm 14$ & $268 \pm 13$ & $<0.05$ \\
Heart dry weight $(\mathrm{mg})$ & $189 \pm 7$ & $146 \pm 7$ & $<0.001$ \\
Heart wt/100 g body wt & $0.087 \pm 0.004$ & $0.055 \pm 0.001$ & $<0.001$ \\
Systolic blood pressure & & & \\
$\quad(\mathrm{mmHg})$ & $176 \pm 7$ & $129 \pm 3$ & $<0.001$ \\
Hematocrit $(\%)$ & $34 \pm 4$ & $48 \pm 1$ & $<0.01$ \\
Plasma Na $(\mathrm{mM})$ & $142 \pm 2$ & $142 \pm 2$ & $\mathrm{NS}$ \\
$\mathrm{K}^{+}(\mathrm{mM})$ & $5.8 \pm 0.2$ & $4.3 \pm 0.1$ & $<0.001$ \\
$\mathrm{Ca}^{2+}(\mathrm{mM})$ & $0.84 \pm 0.07$ & $1.06 \pm 0.04$ & $<0.01$ \\
$\mathrm{Urea}^{2}(\mathrm{mM})$ & $36.4 \pm 6.3$ & $8.2 \pm 0.4$ & $<0.001$ \\
$\mathrm{Creatinine}(\mu \mathrm{M})$ & $165 \pm 21$ & $41 \pm 5$ & $<0.001$ \\
& & & \\
\hline
\end{tabular}

in uremic animals $(P<0.001)$. Systolic blood pressure was moderately elevated in uremic animals $(P<0.001)$, and they had metabolic changes of chronic renal failure, including anemia, hyperkalemia, reduced plasma free calcium, and fourfold increases in plasma urea and creatinine concentrations. Serial blood sampling showed that these increases were present by $7 \mathrm{~d}$ after completion of subtotal nephrectomy, when urea concentration was $37 \pm 4 \mathrm{mM}$ and creatinine was $169 \pm 13 \mu \mathrm{mol} /$ liter $(n=10)$. Similar changes occurred in animals with uremia of 3 wk duration $(n=7)$, used for ${ }^{31} \mathrm{P}$ NMR studies, with plasma urea and hematocrit of $40 \pm 5 \mathrm{~mm}$ and $41 \pm 2 \%$ in uremic animals and $7.6 \pm 1.2 \mathrm{~mm}$ and $52 \pm 4 \%$ in controls, respectively.

Function of isolated working hearts. The function of uremic and control hearts in vitro is illustrated in Figs. 1 and 2. Fig. 1 shows the change in cardiac output as afterload was increased, while left atrial filling pressure was held constant. Cardiac output of hearts from uremic animals was reduced significantly compared with controls $(\mathrm{F}=26.1, P<0.001$ by MANOVA), by $\leq 21 \%$ at an aortic pressure of $70 \mathrm{~cm} \mathrm{H}_{2} \mathrm{O}(P$ $=0.011$ ) (Fig. 1). The reduction appeared to be caused primarily by an impairment in inotropic state, since heart rate in vitro was the same in uremic hearts and controls $(246 \pm 10$ vs $\left.247 \pm 11 \mathrm{~min}^{-1}\right)$. Coronary flow was also lower in uremic hearts

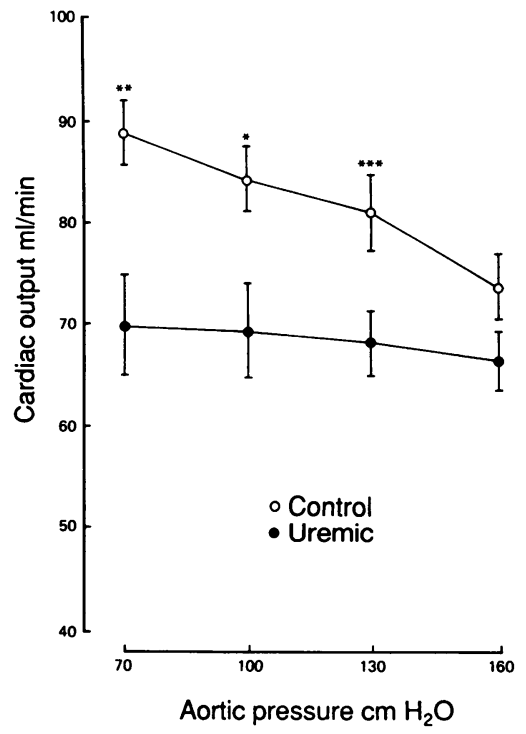

Figure 1. Relationship of cardiac output and stroke volume in uremic and control hearts to left ventricular afterload (aortic pressure). Left atrial filling pressure was held constant at $17.5 \mathrm{~cm} \mathrm{H}_{2} \mathrm{O}$. Values are mean \pm SEM $(* P$ $=0.017 ;{ }^{* *} P=0.011$; $* * * P=0.014$ for comparison between control and uremic).

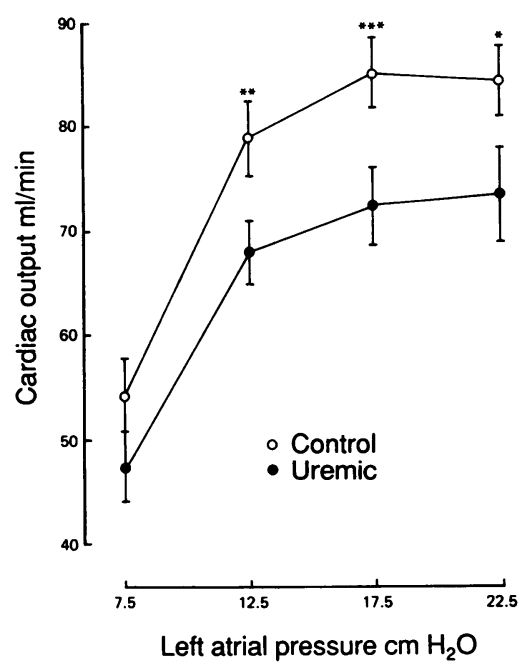

Figure 2. Relationship of cardiac output in uremic and control hearts to left atrial filling pressure (preload). Aortic pressure (afterload) was held constant at $100 \mathrm{~cm} \mathrm{H}_{2} \mathrm{O}$. Values are mean \pm SEM. $\left({ }^{*} P\right.$ $=0.08 ;{ }^{* *} P=0.028$ ***P $P=0.021$ for comparison between control and uremic).

than their controls (e.g., $19.1 \mathrm{vs} 24.5 \mathrm{ml} / \mathrm{min})(P<0.02)$ at aortic pressure of $160 \mathrm{~cm} \mathrm{H}_{2} \mathrm{O}$ ). When afterload was held constant at $100 \mathrm{~cm} \mathrm{H}_{2} \mathrm{O}$, and left atrial filling pressure was increased to generate a Starling curve, a downwards shift of the function curve was apparent (Fig. 2), with lower cardiac output of uremic hearts, than control hearts (F=17.1, $P<0.001$ by MANOVA).

The effects on cardiac performance of altering perfusate $\mathrm{Ca}^{2+}$ concentration are shown in Fig. 3. In control hearts, stepwise increases in perfusate $\mathrm{Ca}^{2+}$ concentration from 0.7 to 5.6 $\mathrm{mM}$ resulted in progressive elevation of cardiac output and heart rate. Cardiac output of uremic hearts was lower than controls at all levels of perfusate calcium $(\mathrm{F}=29.8, P<0.001)$. With high calcium perfusate $(5.6 \mathrm{~mm})$, uremic hearts developed acute dysfunction with a fall in cardiac output $(-4.4 \pm 1.8$ $\mathrm{ml} / \mathrm{min}, P<0.05$ ), in contrast to control hearts, whose cardiac output increased $(+5.7 \pm 1.2 \mathrm{ml} / \mathrm{min}, P<0.01)$. Changes in heart rate in response to calcium were similar in both groups (Fig. 3).

There was no correlation between degree of anemia ( $r$ $=-0.143, P=\mathrm{NS})$ or of ventricular hypertrophy $(r=-0.264$, $P=\mathrm{NS})$ and impairment of cardiac performance in the uremic animals.

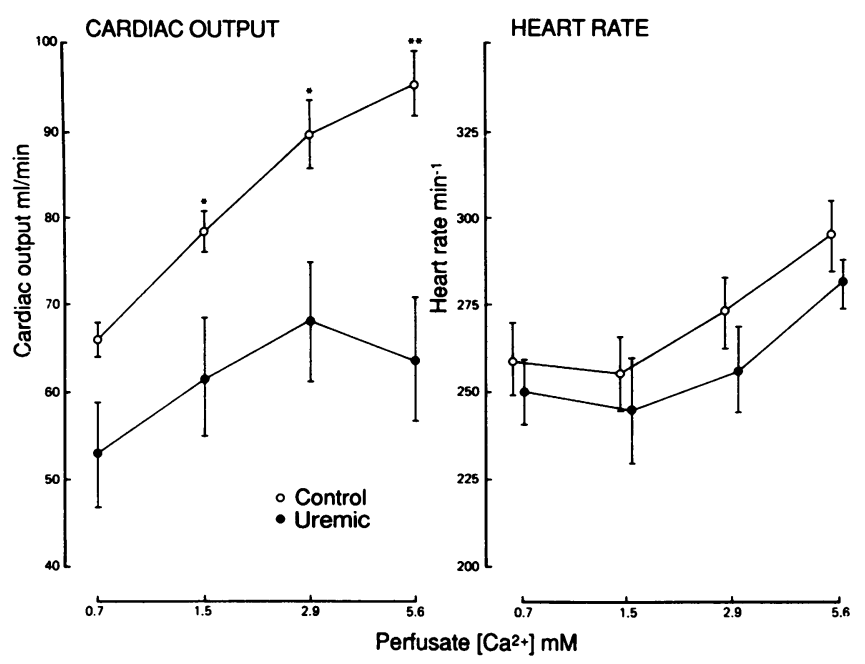

Figure 3. Relationship of cardiac function to perfusate calcium concentration in uremic and control hearts. Values are mean \pm SEM. $\left({ }^{*} P\right.$ $<0.05 ;{ }^{* *} P=0.003$ for comparison between control and uremic). 
Acute effects of urea and creatinine on cardiac function. Hearts from control Wistar rats were perfused with concentrations of urea and creatinine intended to exceed those found in end-stage renal failure. Addition of urea or creatinine resulted in no change in cardiac output, coronary flow, or heart rate (Fig. 4).

${ }^{31} P$ NMR studies. Seven chronically uremic rats and pairfed controls were studied. Baseline ${ }^{31} P$ NMR spectra were accumulated during $30 \mathrm{~min}$ Langendorff perfusion. Typical representative spectra from renal failure and control hearts are illustrated in Fig. 5. There was a marked reduction in basal phosphocreatine concentration in uremic hearts, to $68 \%$ of control levels $(P<0.01)$ (Table II). ATP concentration remained constant, and the phosphocreatine/ATP ratio was reduced by $32 \%$ in uremic hearts ( 1.05 vs $1.54, P<0.005)$. There was no significant difference between uremic and control hearts in the total creatine concentrations $(16.5 \pm 1.0$ vs $16.0 \pm 1.3 \mu \mathrm{mol} / \mathrm{g}$ wet $\mathrm{wt}$ ). Calculation of the free ADP concentration using the creatine kinase equilibrium constant showed it doubled in concentration in the uremic hearts $(P<0.02)$ (Table II). Intracellular $\mathrm{pH}$ was unchanged in uremic hearts, and there was no difference in intracellular free inorganic phosphate concentration.

The effects of 30-min low flow ischemia on renal failure and control hearts are shown in Fig. 6. While the degree of phosphocreatine breakdown was similar, the absolute concentrations of phosphocreatine were more severely reduced in the uremic hearts than in controls. The depletion of ATP was not significantly different in the two groups. However, the release of inosine from the uremic hearts was considerably greater than controls (Fig. 7), indicating a more severe degree of ischemic damage. The degree of intracellular acidosis was similar in both groups (Fig. 8).

\section{Discussion}

The existence of a cardiomyopathic state related specifically to chronic renal failure has been debated $(21,22)$, largely because of the multitude of factors present in patients with renal failure that might impair cardiac function (2). In the present study, it
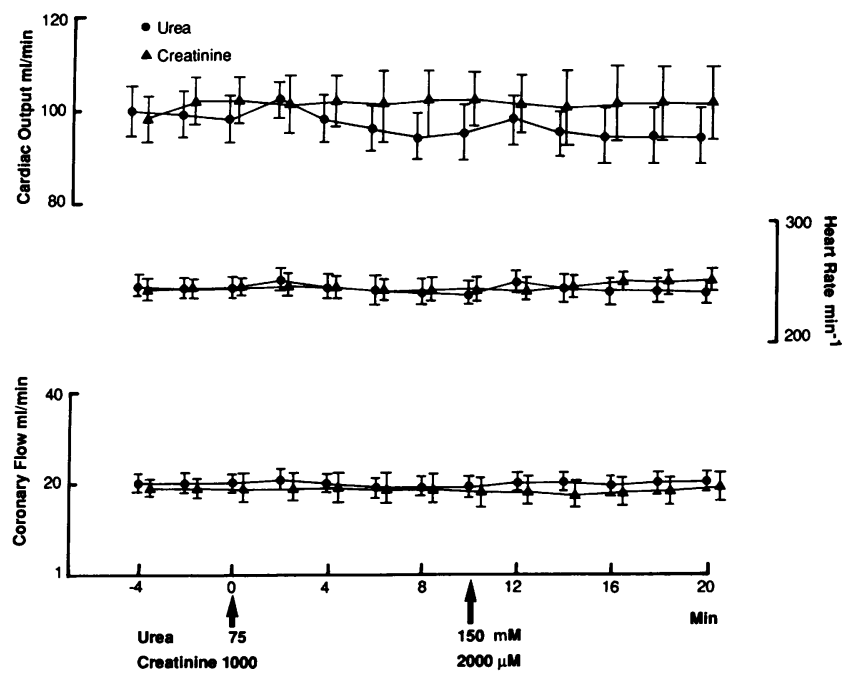

Figure 4. Effect of addition of urea or creatinine to perfusate on cardiac output, heart rate and coronary flow rate of normal hearts ( $n$ $=6$ for each group). Values are mean \pm SEM.

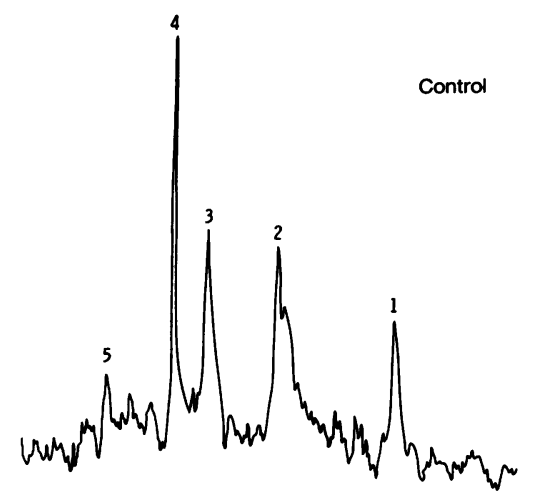

Figure 5. ${ }^{31} \mathrm{P}-\mathrm{NMR}$ spectra from Langendorff-perfused control and uremic hearts. Peaks are $1, \beta$-ATP; 2 , $\alpha$-ATP; 3, $\gamma$-ATP; 4 , phosphocreatine; and 5 ,

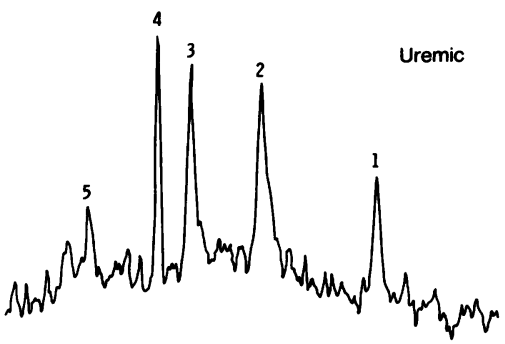
inorganic phosphate. Spectra were accumulated under fully relaxed conditions (see Methods) and quantified against a standard of known concentration (methylene diphosphonate, not shown).

has been possible to control or eliminate many of these factors by employment of a model of subtotal nephrectomy, as well as study of cardiac function and energetics under controlled conditions in vitro. The findings suggest that renal impairment results in abnormal cardiac performance and metabolism, as well as a reduced tolerance to ischemia.

When preload and afterload were independently varied, cardiac output of hearts from uremic animals was significantly reduced in comparison with matched pair-fed controls (Figs. 1 and 2). This reduction was demonstrable in vitro, in the absence of any hormonal or neural influences on the heart. Basal cardiac output of control hearts was $90 \mathrm{ml} / \mathrm{min}$, comparable to the cardiac output in vivo in the rat of $100 \mathrm{ml} / \mathrm{min}$ (23). Furthermore, the decrease in performance of the uremic hearts appeared to be caused by reduced contractile performance, as their heart rate in vitro was the same as that of control hearts.

Of the potential confounding factors that may affect myocardial function in clinical uremia, fluid overload may be discounted in the current study, since both left atrial filling pressure and afterload were carefully controlled. Although hyper-

Table II. Metabolite Concentrations of Uremic and Control Hearts Measured by ${ }^{31} P$ NMR

\begin{tabular}{|c|c|c|c|}
\hline & $\begin{array}{l}\text { Uremic } \\
(n=7)\end{array}$ & $\begin{array}{l}\text { Control } \\
(n=6)\end{array}$ & $P$ \\
\hline $\begin{array}{l}\text { Phosphocreatine } \mu \mathrm{mol} / \mathrm{s} \\
\text { wet wt }\end{array}$ & $4.81 \pm 0.35$ & $7.06 \pm 0.58$ & $<0.01$ \\
\hline ATP $\mu \mathrm{mol} / \mathrm{g}$ wet wt & $4.59 \pm 0.51$ & $4.91 \pm 0.72$ & NS \\
\hline Phosphocreatine/ATP & $1.05 \pm 0.04$ & $1.54 \pm 0.16$ & $<0.005$ \\
\hline ADP $\mu \mathrm{mol} / \mathrm{g}$ wet $\mathrm{wt}$ & $0.052 \pm 0.007$ & $0.024 \pm 0.006$ & $<0.02$ \\
\hline Intracellular pH & $7.05 \pm 0.01$ & $7.04 \pm 0.01$ & NS \\
\hline $\begin{array}{l}\text { Inorganic phosphate } \\
\mu \mathrm{mol} / \mathrm{g} \text { wet wt }\end{array}$ & $1.20 \pm 0.16$ & $1.04 \pm 0.13$ & NS \\
\hline $\begin{array}{l}\text { Total creatine } \mu \mathrm{mol} / \mathrm{g} \\
\text { wet wt }\end{array}$ & $16.5 \pm 1.0$ & $16.0 \pm 1.3$ & NS \\
\hline
\end{tabular}



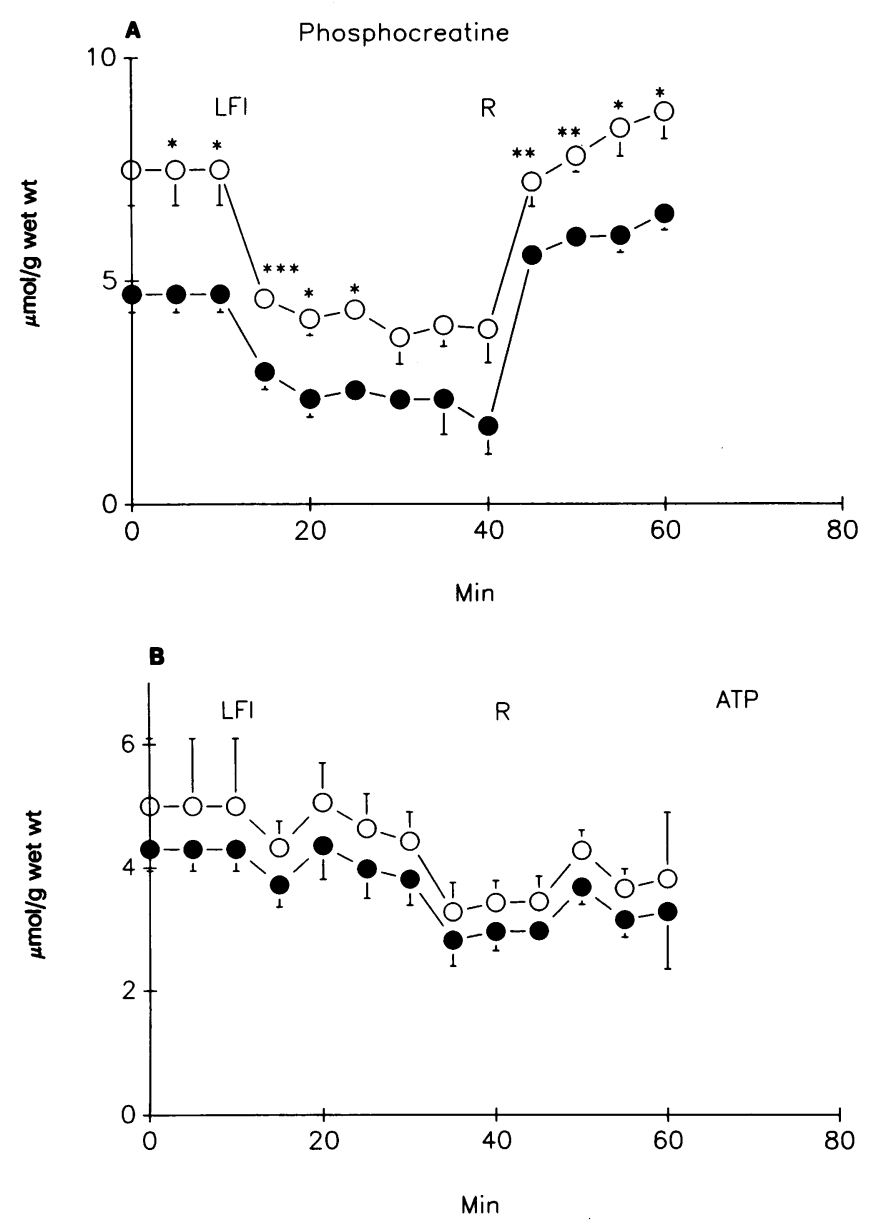

Figure 6. Effects of low flow ischemia on concentrations of phosphocreatine and ATP in uremic and control rat hearts. Hearts were perfused in the isometric mode as described in Methods. Low flow ischemia $(L F I)$ was produced by lowering the perfusion pressure from $70 \mathrm{~cm} \mathrm{H}_{2} \mathrm{O}$ to $15-20 \mathrm{~cm} \mathrm{H}_{2} \mathrm{O}$ for $30 \mathrm{~min}$ followed by 20 -min reperfusion $(R)$. Concentrations of phosphocreatine and ATP were measured using ${ }^{31} \mathrm{P}$ NMR. Results are expressed as the mean $\pm \operatorname{SEM}(n$ $=4),{ }^{*} P<0.05,{ }^{* *} P<0.01,{ }^{* * *} P<0.001 .0-0$, Control; $\bullet-\bullet$, uremic.

tension and cardiac hypertrophy were present, similar studies performed previously in the spontaneously hypertensive rat have shown that cardiac performance of spontaneously hypertensive rat was enhanced both in vitro (13) and in vivo (23, 24 ), despite greater cardiac hypertrophy than that occurring in the uremic model (25). No relationship was observed between the degree of anemia and severity of left ventricular dysfunction, and in clinical studies, severe anemia has been found to have no significant effect on cardiac function (26). Previous experimental studies have suggested that uremic toxins, in particular urea itself, might directly depress cardiac function (3, 27). However, in experimental acute uremia, cardiac function in vivo is augmented (6-8), despite greater increases in urea and creatinine than those occurring in chronic experimental uremia. In the present study, impaired cardiac function was seen in uremic animals when hearts were perfused in vitro with physiological saline containing no urea or other potential toxins. In addition, no direct effect of either urea or creatinine could be demonstrated on cardiac function (Fig. 4).

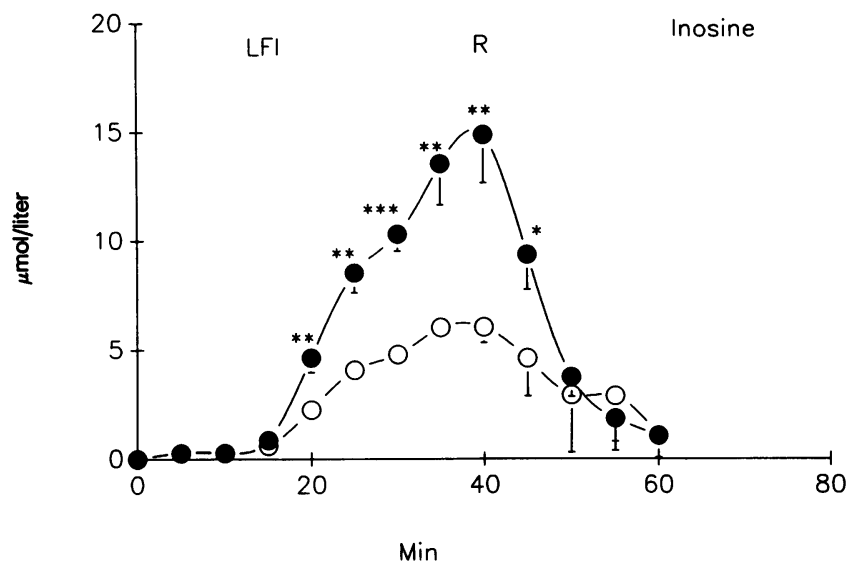

Figure 7. Concentrations of inosine released from uremic and control hearts during $30 \mathrm{~min}$ of low flow ischemia. Hearts were perfused as described in the legend to Fig. 6. Samples of coronary effluent were taken at 5-min intervals throughout the experimental protocol of 30 min low flow ischemia $(L F I)$ and reperfusion $(R)$ and analyzed by HPLC. Results are expressed as the mean $\pm \operatorname{SEM}(n=4),{ }^{*} P<0.05$, ${ }^{* *} P<0.01,{ }^{* * *} P<0.001 .0-0$, Control; $\bullet-\bullet$, uremic.

Despite the difficulty of evaluating cardiac function in uremic patients, several clinical studies also indicate that uremia may be specifically associated with cardiac dysfunction. For example, in patients with low ejection fraction, a significant improvement was seen after hemodialysis (28). Henrich and colleagues were able to dissociate changes in cardiac preload and contractile state, and showed that isovolumic hemodialysis produced an upward shift of the left ventricular function curve (29). This improvement appeared to be related to increased plasma calcium, rather than to correction of acidosis or removal of uremic toxins (30). An invasive study in both dialysis and predialysis patients showed that left ventricular end-diastolic pressure was increased at rest and during exercise, with impaired left ventricular stroke work in response to exercise, indicating cardiac performance may be abnormal even rela-

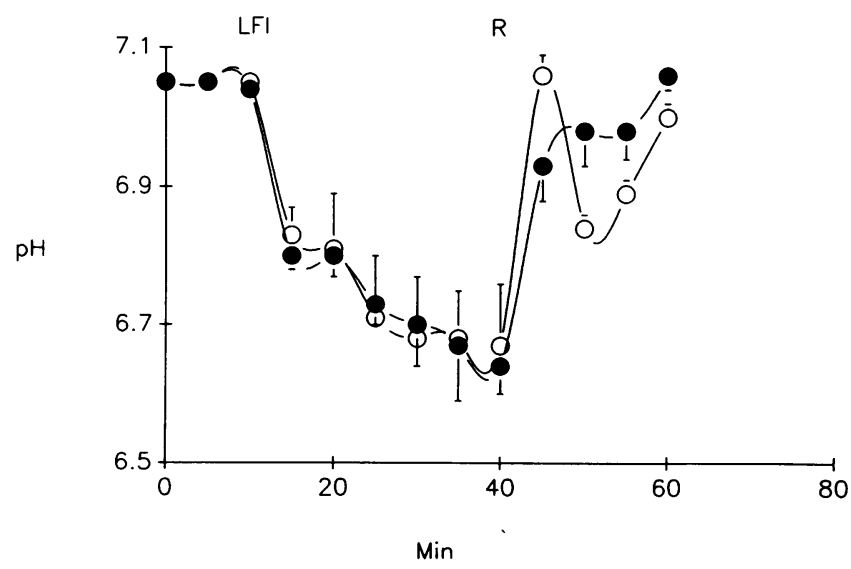

Figure 8. Changes in intracellular pH during low flow ischemia and reperfusion. Hearts were perfused as described previously. Intracellular $\mathrm{pH}$ was determined by ${ }^{31} \mathrm{P}$ NMR using the chemical shift difference between phosphocreatine (set to $0 \mathrm{ppm}$ ) and inorganic phosphate resonances. Results are expressed as the mean $\pm \operatorname{SEM}(n=4)$. $\mathrm{O}+-\mathrm{O}$, Control; $\bullet-\bullet$, uremic. 
tively early in the development of renal failure in man (31). These changes were unrelated to anemia or hypertension.

Assessment of cardiac metabolism in uremic hearts by ${ }^{31} \mathrm{P}$ NMR in the present study demonstrated associated changes in basal cardiac cellular bioenergetics. There were marked reductions in phosphocreatine content and phosphocreatine/ATP ratio, and an increase in calculated free cytosolic ADP concentrations. A decrease in phosphocreatine/ATP ratio implies that in the basal state there is a reduced myocardial energy supply in uremia. Similar reductions in phosphocreatine/ATP ratio have been documented in certain animal models of cardiac hypertrophy, such as hyperthyroidism (15) and development of failure in the aging spontaneous hypertensive rat (32). However, cardiac hypertrophy accompanying experimental chronic anemia does not lead to any change in phosphocreatine content (33). Interestingly, recent clinical studies have shown that in patients with aortic valve disease, it is those who have coexistent heart failure in whom the phosphocreatine/ ATP ratio is depressed (34).

The mechanism of these changes remains uncertain, but is not because of a reduction in creatine kinase activity. A preliminary study (35) has demonstrated no change in total creatine kinase activity in uremic hearts, in contrast to observations in experimental (32) and clinical (36) cardiac hypertrophy and heart failure. Reduced myocardial creatine content, an alternative mechanism $(15,32,36)$, was also excluded as an explanation in the present study (Table II). In addition, the decrease in phosphocreatine may imply an impairment of ATP synthesis or utilization in the uremic myocardium with resulting maintenance of cytosolic ATP concentration via the creatine kinase equilibrium (37), despite a decrease of phosphocreatine. The increase in free cytosolic ADP may itself affect cardiac function adversely, since high concentrations of ADP inhibit myosin ATPase activity $\left(K_{1} \sim 200 \mu \mathrm{M}\right)(38)$ and might exacerbate heart muscle failure (39).

During low flow ischemia, there was a more marked release of inosine from the uremic hearts. Inosine, as an ATP breakdown product, has been widely used as a marker of ischemic damage in vitro $(17,40)$ and thus this observation suggests that myocardial susceptibility to ischemia may be increased in chronic uremia. The differences in inosine release observed cannot be attributed to varying degrees of ischemia in uremic and control hearts, since use of the isometric paced preparation ensures that the output is equivalent in both groups.

Analogy with other settings in which the myocardial phosphocreatine/ATP ratio is reduced $(32,34)$ implies that in this model of experimental renal impairment, the heart is in incipient failure. In keeping with this suggestion, both myocardial function and tolerance of ischemia were impaired. Development of cardiac ischemia itself leads to a reduction in phosphocreatine /ATP ratio (41), together with reduced myocardial concentrations of both metabolites. It is possible that there is a basal reduction in myocardial energy reserve in renal failure, which increases the vulnerability to ischemic damage and to irreversible loss of ATP. The greatly enhanced release of inosine from the uremic heart during ischemia has similarities to the findings of Ingwall et al. (32) in hyperthyroid hearts. In the latter model, there was also a reduced basal phosphocreatine/ ATP ratio and greater susceptibility to hypoxic stress, with loss of ATP and subsequent failure of recovery of function.

The basis of the myocardial contractile impairment and reduction in energy reserve observed in uremic hearts remains unknown. However, the observation that uremic hearts failed in high calcium perfusate, in contrast to control hearts, raises the possibility that disordered calcium utilization may be relevant. Recent studies of congestive heart failure in other experimental models and in patients have shown that abnormalities of intracellular calcium homeostasis are a consistent feature (42). It may be that in chronic renal failure, cytosolic calcium control is impaired, and that the normal relationship between intracellular free calcium and contractile function of the myofilaments is disturbed, with an associated reduction in energy reserves. These possibilities merit further investigation.

\section{Acknowledgments}

A. E. G. Raine was the recipient of a British Heart Foundation Senior Research Fellowship. The support of the British Heart Foundation (BHF NMR Research Group) and the Medical Research Council (United Kingdom) is gratefully acknowledged.

\section{References}

1. Raine, A. E. G. 1988. Cardiovascular complications after renal transplantation. In Kidney Transplantation: Principles and Practice. P. J. Morris, editor. Grune \& Stratton, Inc., New York. 575-599.

2. Capelli, J. P., and H. Kasparian. 1977. Cardiac work demands and left ventricular function in end-stage renal disease. Ann. Intern. Med. 86:261-267.

3. Scheuer, J., and S. W. Stezoski. 1973. The effects of uremic compounds on cardiac function and metabolism. J. Mol. Cell Cardiol. 5:287-300.

4. Massry, S. G. 1984. Parathyroid hormone and uremic myocardiopathy. Contrib. Nephrol. 41:231-239.

5. Rostand, S. G., K. A. Kirk, and E. A. Rutsky. 1984. Dialysis-associated ischemic heart disease: insights from coronary angiography. Kidney Int. 25:653659.

6. Nivatpumin, T., T. Yipintsoi, S. Penpargkul, and J. Scheuer. 1975. Increased cardiac contractility in acute uraemia: interrelationship with hypertension. Am. J. Physiol. 229:501-505.

7. Hennemann, H., G. Hevendehl, H. Arnold, and G. Kissing. 1976. Uremic cardiomyopathy. In Renal insufficiency. A. Heidland, editor. Georg Thieme Publishers, Stuttgart, Germany. 274-280.

8. Zebe, H., B. Rauch, E. Ritz, W. Hasselbach, and W. Goy. 1976. Myocardial metabolism in experimental uremia. In Renal Insufficiency. A. Heidland, editor. Georg Thieme Publishers, Stuttgart, Germany, 268-273.

9. Scheuer, J., T. Nivatpumin, and T. Yipintsoi. 1975. Effects of moderate uremia on cardiac contractile responses. Proc. Soc. Exp. Biol. Med. 150:471-477.

10. Kreusser, W., J. Mann, M. Rambausek, P. Klooker, D. Mehls, and E. Ritz. 1983. Cardiac function in experimental uremia. Kidney Int. 24(Suppl. 15):S83-S88.

11. Ormrod, D., and T. Miller. 1980. Experimental uremia-description of a model producing varying degrees of stable uremia. Nephron. 26:249-254.

12. Taegtmeyer, H., A. F. C. Roberts, and A. E. G. Raine. 1985. Energy metabolism in reperfused heart muscle: metabolic correlates to return of function. J. Am. Coll. Cardiol. 6:864-870.

13. Raine, A. E. G., A. F. C. Roberts, B. S. Manley, J. V. Jones, and J. G. G. Ledingham. 1983. Calcium sensitivity and cardiac performance in genetic and renal models of hypertension. J. Hypertension. 1(Suppl. 2):85-87.

14. Harmsen, E., G. Hogan, G. K. Radda, and A.-M. L. Seymour. 1985. Simultaneous monitoring of intracellular high energy phosphates by ${ }^{31} \mathrm{P}-\mathrm{NMR}$ and extracellular adenosine catabolites in an isometric paced rat heart during low flow ischemia and reperfusion. Proc. Soc. Mag. Res. Med. 1:475-476.

15. Seymour, A.-M. L., H. Eldar, and G. K. Radda. 1990. Hyperthyroidism results in increased glycolytic capacity in the rat heart: ${ }^{31} \mathrm{P}$ NMR study. Biochim. Biophys. Acta. 1055:107-116.

16. Moon, R. B., and R. H. Richards. 1973. Determination of intracellular pH by ${ }^{31} \mathrm{P}$ magnetic resonance. J. Biol. Chem. 248:7276-7278.

17. de Jong, J. W. 1988. Diagnosis of ischemic heart disease with AMP-catabolites. In Myocardial Energy Metabolism. J. W. de Jong, editor. Martinus Nijhoff, Dordrecht, Holland. pp. 237-244.

18. Harmsen, E., J. W. de Jong, and P. W. Serruys. 1981. Hypoxanthine production by ischaemic heart demonstrated by high pressure liquid chromatography of blood purine nucleosides and oxypurines. Clin. Chim. Acta. 115:73-84.

19. Harmsen, E., P. Ph. De Tombe, and J. W. De Jong. 1982. Simultaneous determination of myocardial adenine nucleotides and creatine phosphates by high pressure liquid chromatography. J. Chromatogr. 230:131-136. 
20. Veech, R. L., J. W. R. Lawson, N. W. Cornell, and H. A. Krebs. 1979. Cytosolic phosphorylation potential. J. Biol. Chem. 254:6538-6547.

21. Prosser, D., and V. Parsons. 1975. The case for a specific uraemic myocardiomyopathy. Nephron. 15:4-7.

22. Gueron, M., G. M. Berlyne, E. Nord, and J. Ben Ari. 1975. The case against the existence of a specific uraemic myocardiopathy. Nephron. 15:2-4.

23. Lundin, S., P. Friberg, and M. Hallback-Norlander. 1982. Left ventricular hypertrophy improves cardiac performance in spontaneously hypertensive rats. Acta Physiol. Scand. 114:321-328.

24. Friberg, P., S. Lundin, B. Folkow, and M. Hallback-Norlander. 1983. Left ventricular function in spontaneous and renal hypertension in rats. $J$. Hypertension. 1(Suppl. 2):269-271.

25. Rambausek, M., E. Ritz, G. Mall, O. Mehls, and H. Katus. 1985. Myocardial hypertrophy in rats with renal insufficiency. Kidney Int. 28:775-782.

26. Warrier, E. R., K. G. Balakrishnan, K. Sankaran, and G. D. Gupta. 1981. Systolic time intervals in chronic severe anaemia and effect of diuretic and digitalis. Br. Heart J. 46:80-83.

27. Kersting, F., H. Brass, and R. Heintz. 1978. Uremic cardiomyopathy: studies on cardiac function in the guinea pig. Clin. Nephrol. 10:109-113.

28. Hung, J., P. J. Harris, R. F. Uren, D. J. Tiller, and D. T. Kelly. 1980. Uraemic cardiomyopathy: effect of haemodialysis on left ventricular function in end-stage renal failure. $N$. Engl. J. Med. 302:547-551.

29. Nixon, J. V., J. H. Mitchell, J. J. McPhaul, and W. L. Henrich. 1983. Effect of hemodialysis on left ventricular function. Dissociation of changes in filling volume and in contractile state. J. Clin. Invest. 71:377-384.

30. Henrich, W. L., J. M. Judson, and J. V. Nixon. 1984. Increased ionized calcium and left ventricular contractility during hemodialysis. N. Engl. J. Med. 310:19-23.

31. Pehrsson, K., R. Jonasson, and L.-E. Lins. 1984. Cardiac performance in various stages of renal failure. Br. Heart J. 52:667-673.

32. Ingwall, J. S., D. E. Atkinson, K. Clarke, and J. K. Fetters. 1990. Energetic correlates of cardiac failure: changes in the creatine kinase system in the failing myocardium. Eur. Heart J. ii:108-115.
33. Field, M. L., C. Thompson, C. Henderson, A.-M. L. Seymour, and G. K. Radda. 1992. Changes in the myocardial creatine kinase isozyme profile with progression and regression of volume overload eccentric hypertrophy. Biochem. Soc. Trans. 20:172S.

34. Conway, M. A., J. Allis, R. Ouwerkerk, T. Niioka, B. Rajagopalan, and G. K. Radda. 1991. Detection of low phosphocreatine to ATP ratio in failing hypertrophied human myocardium by ${ }^{31} \mathbf{P}$ magnetic resonance spectroscopy. Lancet. 338:973-976.

35. Field, M. L., Y. Green, G. K. Radda, C. Henderson, and A.-M. L. Seymour. 1992. Creatine kinase isozyme profile in myocardial pressure overload, volume overload and idiopathic hypertrophy. J. Mol. Cell. Cardiol. 24(Suppl. 1). S248.

36. Ingwall, J. S., M. F. Kramer, M. A. Fifer, B. H. Lorell, R. Shemin, W. Grossman, and P. D. Allen. 1985. The creatine kinase system in normal and diseased human myocardium. N. Engl. J. Med. 313:1050-1054.

37. Meyer, R. A., H. L. Sweeney, and M. J. Kushmenick. 1984. A simple analysis of the 'phosphocreatine shuttle.' Am. J. Physiol. 246:C365-377.

38. Trentham, D. R., J. F. Eccleston, and C. R. Bagshaw. 1976. Kinetic analysis of ATPase mechanism. Q. Rev. Biophysics. 9:217-281.

39. Matthews, P. M., D. J. Taylor, and G. K. Radda. 1986. Biochemical mechanisms of acute contractile failure in the hypoxic rat heart. Cardiovasc. Res. 20:13-19.

40. Van Belle, H., F. Goossens, and S. J. Wynant. 1986. Formation and release of purine catabolites during hypoperfusion, anoxia and ischemia. Am. J. Physiol. 252:H886-H893.

4i. Weiss, R. G., P. A. Bottomley, C. J. Hardy, and G. Gerstenblith. 1990. Regional myocardial metabolism of high-energy phosphates during isometric exercise in patients with coronary artery disease. N. Engl. J. Med. 323:15931600.

42. Morgan, J. P. 1991. Mechanisms of disease: abnormal intracellular modulation of calcium as a major cause of cardiac contractile dysfunction. $N$. Engl. J. Med. 325:625-632. 